\title{
Hemodynamic and cardiorespiratory responses to various arm cycling regimens in men with spinal cord injury
}

\author{
Todd A. Astorino ${ }^{1}$
}

Received: 4 November 2018 / Revised: 4 December 2018 / Accepted: 10 December 2018

(C) International Spinal Cord Society 2019

\begin{abstract}
Study design Repeated measures within-subjects crossover study.

Objectives High intensity interval exercise (HIIE) elicits higher oxygen consumption $\left(\mathrm{VO}_{2}\right)$ and heart rate (HR) versus moderate intensity continuous exercise (MICE) in men with spinal cord injury (SCI). No study has compared hemodynamic responses to HIIE versus MICE in SCI. In this study, we determined hemodynamic and cardiorespiratory responses to different bouts of arm cycling in men with SCI.

Setting Human Performance Laboratory, San Diego, CA.

Methods Five men (age and injury duration $=42.6 \pm 16.1 \mathrm{yr}$ and $9.9 \pm 7.6 \mathrm{yr}$ ) with SCI participated in the study. $\mathrm{VO}_{2}$ peak and peak power output were initially assessed. Subsequent visits included MICE, HIIE, sprint interval exercise (SIE), and a no-exercise control (CON). Energy expenditure was matched across modes and equal to $100 \pm 10 \mathrm{kcal}$. During the bouts, cardiac output $(\mathrm{CO})$, stroke volume (SV), $\mathrm{HR}$, and $\mathrm{VO}_{2}$ were measured.

Results Heart rate, SV, and $\mathrm{CO}$ increased in response to all exercise bouts and were higher during exercise versus CON. During HIIE and SIE, heart rate approached $90 \%$ of maximum, and stroke volume increased by $40 \%$ which was higher $(p<$ 0.05) versus MICE and CON. In addition, exercise led to a two (MICE) to threefold increase in CO (HIIE and SIE) although it was not different from CON. $\mathrm{VO}_{2}$ during SIE and HIIE was higher $(p<0.05)$ versus MICE.

Conclusions Similar to results in non-disabled populations, HIIE and SIE elicit near-maximal values of SV and CO.
\end{abstract}

\section{Introduction}

Individuals with spinal cord injury (SCI) have two-fold higher risk of cardiovascular disease versus able-bodied individuals [1] due to higher incidence of physical inactivity, obesity, diabetes, and dyslipidemia. This enhanced risk merits implementation of prevention strategies to improve health in this population [2-4]. Co-morbidities associated with SCI are related to disruption of autonomic control below the injury as well as skeletal muscle atrophy and inactivity resulting from reduced motor function [5-7]. Persons with SCI show attenuated increases in heart rate (HR), stroke volume (SV), and cardiac output (CO) which reduce exercise capacity [8]. In addition, impaired sympathetic input below

Todd A. Astorino

astorino@csusm.edu

1 Department of Kinesiology, CSU—San Marcos, San Marcos, USA the injury level reduces myocardial contractility and blood redistribution during exercise [9] which elicits lower extremity venous blood pooling and attenuated venous return and cardiac filling [10-12].

Regular physical activity significantly enhances cardiovascular function in persons with SCI, but their responses differ versus able-bodied adults [13]. For example, SV is higher and HR is lower in paraplegics compared to the able-bodied during submaximal exercise, which leads to similar CO [9]. Davis and Shepherd [14] showed a minimal increase in SV and CO during arm ergometry in active and inactive men with paraplegia. Overall, hemodynamic responses to exercise are blunted which not only increases risk of atherosclerosis and associated co-morbidities, but also impairs individuals' ability to improve cardiovascular function via exercise training.

In non-disabled adults, completion of high intensity interval training (HIIT) significantly increases $\mathrm{VO}_{2} \max$ and insulin sensitivity similar to moderate intensity continuous exercise (MICE) which reduces chronic disease risk [15-17]. Interval training entails repeated bursts of intense exercise $\left(85-100 \% \quad \mathrm{HR}_{\max }\right)$ interspersed with active 
recovery. A more intense form of HIIT is sprint interval exercise (SIE) which requires brief supramaximal efforts at workloads greater than $\mathrm{VO}_{2}$ max. Recent data show similar adaptations in response to SIE versus MICE with a five-fold lower time commitment [18].

In active men with SCI [19], acute bouts of high intensity interval exercise (HIIE) elicit higher oxygen consumption and HR compared to MICE reflecting near-maximal cardiorespiratory strain. Whether these elevated responses are associated with a near-maximal $\mathrm{CO}$ during HIIE performed in this population is unknown. In able-bodied men, Zafeiridis et al. [20]. compared hemodynamic responses to MICE (70\% peak power output (PPO) and short and long interval exercise at 110 and $95 \%$ PPO. Peak $\mathrm{CO}$ and $\mathrm{VO}_{2}$ were significantly higher in the long interval exercise versus MICE and short interval exercise; however, SV was similar between bouts. Another study [21] in able-bodied individuals exhibited similar CO in SIE compared to ramp exercise to $\mathrm{VO}_{2}$ max which was consequent with higher peak SV in SIE and higher peak HR in ramp exercise. To our knowledge, acute hemodynamic responses to HIIE have not been examined in SCI. Understanding the hemodynamic responses to such protocols may elucidate potential exercisebased strategies to improve cardiovascular function in SCI.

Although HIIE and SIE seem to be well-tolerated in men with SCI [19], research is warranted to determine changes in hemodynamic and cardiorespiratory variables to further explore the potential use of these exercise modalities in this population in an attempt to augment cardiometabolic health through intense exercise programming. This pilot study assessed changes in hemodynamic variables during various arm cycling regimens in men with SCI. It was hypothesized that HIIE and SIE would elicit greater increases in CO, SV, and HR compared to MICE.

\section{Methods}

\section{Participants}

Habitually active men with SCI completed the study, whose physical traits are depicted in Table 1. Habitual activity was measured using the Physical Activity Scale for Individuals with Physical Disabilities [22]. Participants engaged in $11.8 \pm 2.5 \mathrm{~h}$ of physical activity per week including adapted surfing, horseback riding, arm ergometry, resistance training, locomotor training, and functional electrical stimulation cycling. Inclusion criteria were men ages 18-60 yr, injury at or below C5, non-smokers, adequate hand function, physician permission to participate in exercise, and low risk for cardiometabolic disease [23]. Informed consent was obtained from each participant, and experimental procedures were approved by the University Institutional Review Board.

\section{Design}

A repeated measures within-subjects crossover design was used. Participants completed five sessions separated by at least $48 \mathrm{~h}$. Subjects arrived at the lab between 800 and 900 am after a 12-h fast. Participants abstained from vigorous exercise, alcohol, and caffeine in the preceding $24 \mathrm{~h}$. Initially, $\mathrm{VO}_{2}$ peak and PPO were assessed. Order of subsequent sessions was randomized for each participant using software (http://www.randomizer.org/) and consisted of MICE, HIIE, SIE, and no exercise control (CON). MICE, HIIE, and SIE had an energy expenditure equal to $100 \pm 10 \mathrm{kcal}$, as data stemmed from a larger study examining appetite responses to exercise.

\section{Baseline session}

Initially, body composition was measured via Dual Energy X-Ray Absorptiometry (GE Lunar Prodigy Advance, Madison, WI, USA). Body mass, fat, and fat free mass were determined. Subsequently, $\mathrm{VO}_{2}$ peak was measured via progressive exercise on a wall-mounted arm ergometer (Angio Lode, Groningen, Norway) starting at a power output of $7 \mathrm{~W}$ for $5 \mathrm{~min}$. The ergometer was positioned so the shoulder was aligned with the crank pedal. Subjects exercised until volitional exhaustion at a self-selected cadence $>30 \mathrm{rev} / \mathrm{min}$. Work rate increased by $3-8 \mathrm{~W} / \mathrm{min}$ for tetraplegics and $13 \mathrm{~W} / \mathrm{min}$ for paraplegics. Gas exchange data were obtained every $15 \mathrm{~s}$ using a metabolic
Table 1 Participant physical characteristics

\begin{tabular}{llcllllll}
\hline Participant & Age $(\mathrm{yr})$ & TSI $(\mathrm{yr})$ & LOI & COMP & Height $(\mathrm{cm})$ & Mass $(\mathrm{kg})$ & BF $(\%)$ & PA (h/wk) \\
\hline 1 & 59 & 21.0 & C5 & IC & 175.3 & 62.7 & 23.9 & 10 \\
2 & 42 & 2.8 & T9 & IC & 195.6 & 72.1 & 11.1 & 14 \\
3 & 25 & 9.0 & T10 & IC & 177.8 & 66.2 & 26.6 & 10 \\
4 & 58 & 13.5 & C7 & IC & 180.3 & 88.5 & 41.9 & 10 \\
5 & 28 & 3.3 & T6 & C & 177.8 & 71.4 & 19.6 & 15 \\
Mean \pm SD & $42.0 \pm 16.0$ & $9.9 \pm 7.6$ & NA & NA & $181.4 \pm 8.1$ & $72.2 \pm 9.9$ & $24.6 \pm 11.3$ & $11.8 \pm 2.5$ \\
\hline
\end{tabular}

TSI time since injury, $L O I$ level of injury, $T$ thoracic, $C$ cervical, $C O M P$ injury completeness, $I C$ incomplete, $C$ complete, $B F$ body fat, $P A$ physical activity, $N A$ non-applicable 
cart (ParvoMedics TrueOne, Sandy, UT, USA) and face mask (Hans Rudolph Inc., Shawnee, KS, USA). Peak power output was determined as the intensity coincident with exhaustion and was used to determine intensities for subsequent sessions.

\section{Assessment of hemodynamic function}

Before exercise, subjects rested for three minutes, and blood pressure (BP) was taken via manual sphygmomanometry (Omron Healthcare Incorporate, Bannockburn, IL, USA) on both arms to determine resting BP. Subsequently, the participant was prepared for assessment of hemodynamic responses using thoracic impedance (PhysioFlow ${ }^{\circledR}$, Manatec, Strasbourg, France) following standardized procedures [24]. CO, SV, and HR were determined every $15 \mathrm{~s}$ during exercise. In able-bodied individuals, thoracic impedance was validated to assess $\mathrm{CO}$ during exercise up to $\mathrm{VO}_{2} \max$ $[24,25]$. Peak HR, SV, and $\mathrm{CO}$ were determined as the highest value at any point during exercise. For $30 \mathrm{~min}$ postexercise, hemodynamic data were also collected, and participants were instructed to perform quiet tasks including reading. Rest and warm-up values were averaged from the last three successive values. Experimental trials were divided into 10 segments, and each segment represented $10 \%$ completion. For HIIE and SIE, values for each segment were calculated from the last two values during exercise and the first value in recovery, which were averaged. The postexercise phase was divided into four segments, and HR, SV, and $\mathrm{CO}$ were averaged from the last three successive values. Arterio-venous oxygen difference $\left(\mathrm{a}-\mathrm{vDO}_{2}\right.$ in $\left.\mathrm{mL} / \mathrm{dL}\right)$ was calculated by dividing $\mathrm{VO}_{2}(\mathrm{~mL} / \mathrm{min})$ by $\mathrm{CO}(\mathrm{L} / \mathrm{min})$.

\section{Experimental trials}

Sessions began with a 5 min warm up at $10 \%$ PPO. MICE required continuous cycling at $35 \%$ PPO. HIIE consisted of repeated $60 \mathrm{~s}$ bouts at $85 \%$ PPO with $120 \mathrm{~s}$ recovery at $10 \%$ PPO, while SIE required $30 \mathrm{~s}$ bouts at $115 \%$ PPO separated by $90 \mathrm{~s}$ recovery at $10 \%$ PPO. All trials ended with a $2 \mathrm{~min}$ passive recovery. During CON, subjects remained seated for $30 \mathrm{~min}$ while gas exchange and hemodynamic data were obtained.

\section{Rating of perceived exertion and blood lactate concentration}

Rating of perceived exertion [26] was acquired pre-exercise and at $25,50,75$, and $100 \%$ of session completion. This measure was described by instructing participants to report perception of exertion based on their breathing, fatigue, and $\mathrm{HR}$ at that moment. Blood lactate concentration was measured pre-exercise as well as at 50 and $100 \%$ of session completion. Since participants were using their arms to move the ergometer, at each timepoint they briefly stopped cranking with one arm and a fingertip blood sample was acquired from the non-exercising limb using a lancet (Owen Mumford, Inc., Marietta, GA) and portable monitor (Lactate Plus, Nova Biomedical, Waltham, MA).

\section{Data analysis}

Data are reported as mean \pm standard deviation (SD) and were analyzed using SPSS (Version 24.0, Armonk, NY). The Shapiro Wilks test was used to assess normality. Oneway ANOVA with repeated measures was used to compare session duration between bouts. Two-way ANOVA with repeated measures was used to examine differences in variables across bout (HIIE, SIE, MICE, and CON) and time. The Greenhouse-Geisser correction was used to account for unequal variances across groups. If a significant F ratio was obtained, Tukey's post hoc test was used to identify differences between means. Effect size was determined using partial eta-squared $\left(\eta \frac{2}{p}\right)$. Alpha level was established as $p<0.05$. I certify that all applicable institutional and governmental regulations concerning the ethical use of human volunteers were followed during the course of this research.

\section{Results}

All participants completed the study. Results from the graded exercise test are depicted in Table $2 . \mathrm{VO}_{2}$ peak was equal to $1.5 \pm 0.8 \mathrm{~L} / \mathrm{min}$ which represents typical values in SCI [27-30].

Duration required to expend $100 \pm 10 \mathrm{kcal}$ was significantly different between regimens $\left(\mathrm{F}_{2,8}=12.2, p=0.04\right.$, $\left.\eta \frac{2}{p}=0.75\right)$. Post hoc analysis revealed SIE duration was significantly lower than MICE $(24.3 \pm 11.8$ vs. $30.0 \pm$ $12.9 \mathrm{~min}$ ) but similar to HIIE $(27.5 \pm 11.7 \mathrm{~min})$. RPE increased across time $\left(\mathrm{F}_{4,16}=93.5, p=0.001, \eta \frac{2}{p}=0.85\right)$ and there was a significant timeXbout interaction $\left(\mathrm{F}_{12,45}=\right.$ $\left.8.4, p=0.004, \eta \frac{2}{p}=0.61\right)$. End-exercise RPE was higher in HIIE, SIE, and MICE versus CON. Blood lactate concentration increased across time $(p<0.001)$ and was higher in response to SIE $(6.1 \pm 2.0 \mathrm{mM})$ versus MICE $(1.6 \pm$ $0.3 \mathrm{mM})$, but not HIIE $(4.2 \pm 1.1 \mathrm{mM})$.

\section{Changes in hemodynamics in response to arm cycling}

HR significantly increased across time $\left(F_{15,60}=19.3, p=\right.$ $\left.0.004, \eta \frac{2}{p}=0.83\right)$ and there was a main effect of bout $\left(F_{3,12}\right.$ $\left.=16.0, p=0.013, \eta \frac{2}{p}=0.80\right)$ and a significant timeXbout interaction $\left(\mathrm{F}_{45,180}=6.4, p=0.003, \eta \frac{2}{p}=0.73\right)$ (Fig. 1a). 
Peak HR was equal to $129 \pm 30,128 \pm 30,108 \pm 16$, and $75 \pm 9 \mathrm{~b} / \mathrm{min}$ in SIE, HIIE, MICE, and CON, respectively. Post hoc analysis revealed significantly higher exercise HR in HIIE and SIE versus CON, but no difference in HR during MICE versus CON.

SV significantly increased across time $\left(F_{15,60}=11.3, p\right.$ $\left.=0.005, \eta \frac{2}{p}=0.73\right)$ and differed across bouts $\left(F_{3,12}=10.8\right.$, $p=0.005, \eta 2 / \mathrm{p}=0.73)$, and there was a timeXbout interaction $\left(F_{45,180}=3.0, p=0.04, \eta \frac{2}{p}=0.41\right)$ (Fig. 1b). Compared to rest, at end-exercise, $\mathrm{SV}$ increased by $41-42 \%$ for

Table 2 Gas exchange and hemodynamic data in response to graded exercise testing in men with spinal cord injury. (Mean \pm SD)

\begin{tabular}{lc}
\hline Parameter & Value \\
\hline $\mathrm{VO}_{2}$ peak $(\mathrm{L} / \mathrm{min})$ & $1.5 \pm 0.8$ \\
$\mathrm{VO}_{2}$ peak $(\mathrm{mL} / \mathrm{kg} / \mathrm{min})$ & $21.9 \pm 12.6$ \\
$\mathrm{VCO}_{2}$ peak $(\mathrm{L} / \mathrm{min})$ & $1.7 \pm 1.1$ \\
$\mathrm{~V}_{\mathrm{E}}(\mathrm{L} / \mathrm{min})$ & $64.5 \pm 44.2$ \\
$\mathrm{RER}$ & $1.1 \pm 0.2$ \\
Test duration $(\mathrm{min})$ & $13.7 \pm 1.8$ \\
PPO $(\mathrm{W})$ & $100.4 \pm 56.3$ \\
$\mathrm{HRpeak}(\mathrm{b} / \mathrm{min})$ & $146.3 \pm 44.2$ \\
Stroke volume $(\mathrm{mL})$ & $116.2 \pm 25.4$ \\
Cardiac output $(\mathrm{L} / \mathrm{min})$ & $17.0 \pm 9.9$ \\
Arteriovenous $\mathrm{O}_{2}$ difference $(\mathrm{mL} / \mathrm{dL})$ & $8.8 \pm 1.3$ \\
\hline
\end{tabular}

$R E R$ respiratory exchange ratio, $P P O$ peak power output
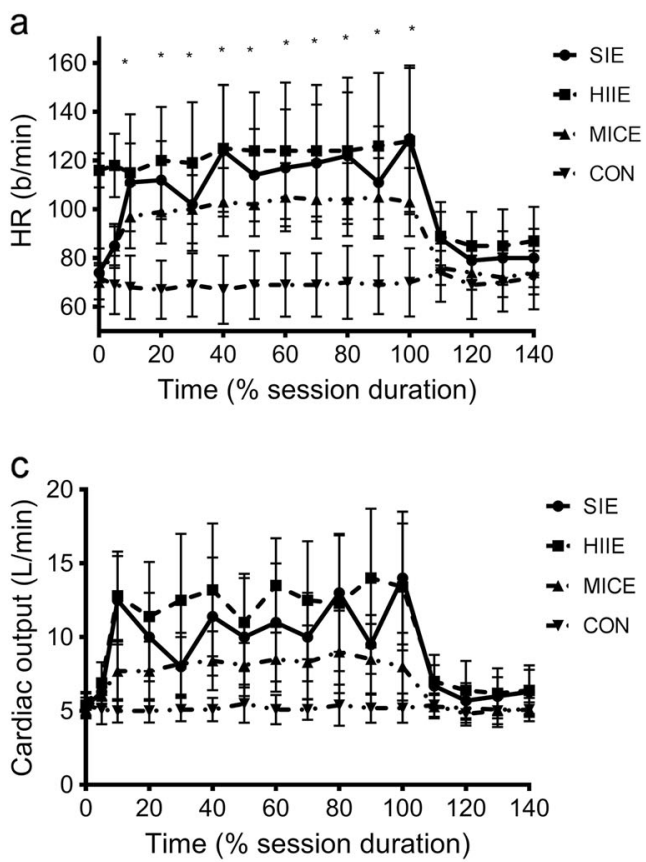

Fig. 1 Differences in a heart rate, $\mathbf{b}$ stroke volume, $\mathbf{c}$ cardiac output, and $\mathbf{d}$ arteriovenous oxygen difference in response to HIIE, SIE, MICE, and CON. (mean \pm SD). The first two data points and last four data points represent values taken pre-exercise and at the end of the
HIIE and SIE, and 9\% for MICE, and peaked at $101 \pm 13$, $102 \pm 29$, and $80 \pm 12 \mathrm{~mL} /$ beat, respectively, with values during SIE and HIIE significantly higher than pre-exercise and recovery. Post hoc analyses exhibited that peak SV in SIE and HIIE was higher than MICE and CON.

Results showed a significant difference in $\mathrm{CO}$ across time $\left(F_{15,60}=11.2, p=0.01, \eta \frac{2}{p}=0.74\right)$ and a main effect of bout $\left(F_{3,12}=12.2, p=0.02, \eta \frac{2}{p}=0.75\right)$ and timeXbout interaction $\left(F_{45,180}=4.7, p=0.04, \eta \frac{2}{p}=0.26\right)$ (Fig. 1c). $\mathrm{CO}$ increased almost threefold from rest to peak exercise during SIE $(5.3 \pm 0.6 \mathrm{~L} / \mathrm{min}$ to $14.0 \pm 4.5 \mathrm{~L} / \mathrm{min})$ and HIIE $(5.4 \pm 0.9 \mathrm{~L} / \mathrm{min}$ to $14.1 \pm 4.7 \mathrm{~L} / \mathrm{min})$, and almost twofold for MICE $(5.1 \pm 0.4 \mathrm{~L} / \mathrm{min}$ to $9.0 \pm 2.8 \mathrm{~L} / \mathrm{min})$, but post hoc analysis revealed that $\mathrm{CO}$ was unchanged during exercise. There was no difference in any $\mathrm{CO}$ value between the exercise bouts and CON despite the approximately 50\% higher CO value in SIE and HIIE versus MICE and threefold higher value in SIE and HIIE versus CON.

A-vDO 2 significantly increased across time $\left(F_{11,44}=9.5\right.$, $\left.p=0.003, \eta \frac{2}{p}=0.70\right)$ and there was a main effect of bout $\left(F_{3,12}=25.4, p=0.004, \eta \frac{2}{p}=0.86\right)$, but no timeXbout interaction $\left(F_{33,132}=1.9, p=0.18, \eta \frac{2}{p}=0.33\right)$. Compared to pre-exercise, post hoc analyses showed a significant increase in a- $\mathrm{vDO}_{2}$ during SIE, HIIE, and MICE (Fig. 1d). In addition, peak values were higher in response to exercise $(9.4 \pm 2.2 \mathrm{~mL} / \mathrm{dL}, 8.6 \pm 2.0 \mathrm{~mL} / \mathrm{dL}$, and $7.5 \pm 1.8 \mathrm{~mL} / \mathrm{dL}$ for SIE, HIIE, and MICE) versus CON $(4.9 \pm 1.1 \mathrm{~mL} / \mathrm{dL})$.
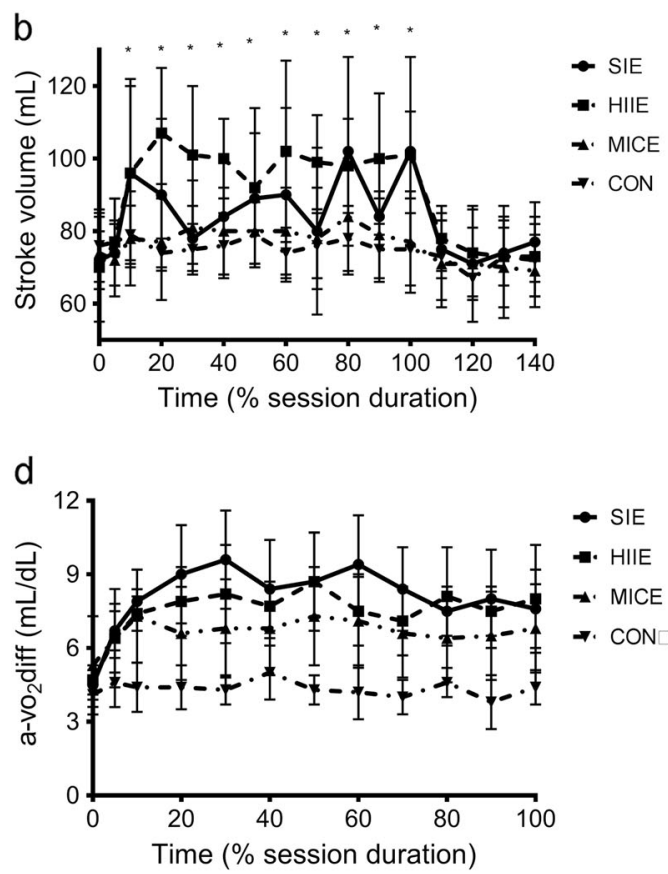

warm-up as well as throughout the $30 \mathrm{~min}$ recovery period. a *significant difference in HR between HIIE/SIE and CON; $\mathbf{b} *$ significant difference in SV for SIE and HIIE between exercise and all other data points; (c) 


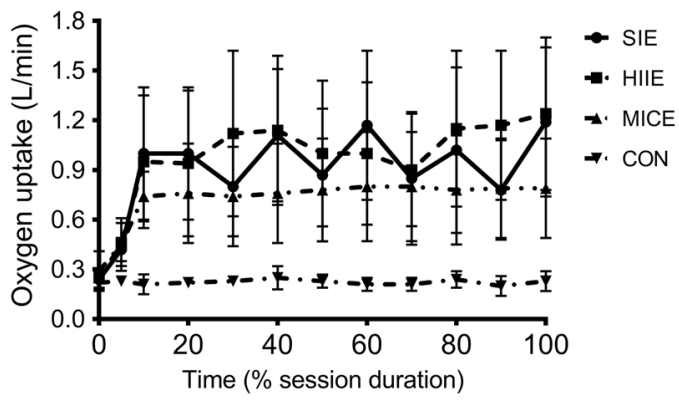

Fig. 2 Differences in oxygen uptake in response to HIIE, SIE, MICE, and $\mathrm{CON}$. (mean $\pm \mathrm{SD})$

\section{Changes in oxygen uptake in response to arm cycling}

$\mathrm{VO}_{2}$ increased across time $\left(F_{11,44}=8.8, \quad p=0.02\right.$, $\left.\eta \frac{2}{p}=0.69\right)$, and a timeXbout interaction was observed $\left(F_{33,132}=3.9, p=0.04, \eta \frac{2}{p}=0.49\right)$. Additionally, there was a main effect of bout $\left(F_{3,12}=13.7, p=0.01, \eta_{p}^{2}=0.77\right)$. $\mathrm{VO}_{2}$ was equal to $0.24 \mathrm{~L} / \mathrm{min}$ at rest and peaked during SIE, HIIE, and MICE to equal $1.2 \pm 0.5 \mathrm{~L} / \mathrm{min}, 1.3 \pm 0.4 \mathrm{~L} / \mathrm{min}$, and $0.8 \pm 0.3 \mathrm{~L} / \mathrm{min}$, respectively, which was substantially higher than $\mathrm{CON}(0.2 \pm 0.1 \mathrm{~L} / \mathrm{min})$ (Fig. 2). Post hoc analysis showed no differences in $\mathrm{VO}_{2}$ across time within bouts or across bouts.

\section{Discussion}

We compared hemodynamic responses to HIIE and SIE versus MICE in men with SCI. Interval training was welltolerated in all participants and no adverse events occurred, which suggests its potential utility in this population especially considering their low fitness level and the documented efficacy of interval training to enhance $\mathrm{VO}_{2}$ max and health status in non-disabled persons. Results show substantial increases in hemodynamic and cardiorespiratory variables with HIIE and SIE compared to CON, but in some cases they were not significantly higher than MICE. Overall, the cardiovascular strain of interval-based arm ergometry is substantial and is met primarily by an increase in HR rather than SV.

Our data showing near-maximal HR eliciting $88 \%$ and $87 \% \mathrm{HR}_{\text {peak }}$ parallel values demonstrated during interval exercise in adults with SCI [19] as well as cardiac patients [31], in which higher HR was evident during HIIE versus MICE. Despite discrepant intensity and volume, HIIE and SIE seem to elicit similar near-maximal levels of cardiac work in men with paraplegia or tetraplegia. In able-bodied adults, higher intensity exercise such as interval training leads to superior increases in $\mathrm{VO}_{2} \mathrm{max}$ than moderate exercise which is beneficial to overall health status. In fact,
Nightingale et al. [32] proposed that HIIT may be a viable alternative to MICE in persons with SCI to markedly improve fitness and health status. This is an important consideration since some data show that chronic MICE does not alter many outcomes related to cardiometabolic health in persons with SCI [33]. Our data show that persons with SCI can tolerate various interval regimes and that arm cycling at these intensities indeed elicits the required cardiorespiratory strain characteristic of interval training.

Heart rate accounts for approximately $63 \%$ of the increase in $\mathrm{CO}$ in able-bodied adults [34] and 67\% in paraplegics completing graded arm exercise [35]. Our data show that HR accounts for $60 \%$ of the increase in $\mathrm{CO}$ during HIIE and SIE, suggesting that HR primarily contributes to increased oxygen delivery during interval training in SCI, similar to previous studies using submaximal exercise in SCI $[9,14,30]$. Higher intensities elicit higher sympathetic responses and thus a compensatory tachycardia which was observed in three of our participants with thoracic injury, whose peak HR approached values seen in ablebodied individuals performing arm cycling. Overall, in persons with SCI, HIIE and SIE elicit a marked increase in $\mathrm{HR}$ to increase $\mathrm{CO}$ to near-maximal values.

Previous findings show minimal changes in SV in men with paraplegia completing graded arm ergometry $[9,36]$ which oppose our results from the interval-based bouts (Fig. 1b). These discrepant data are likely due to different participants and methods of hemodynamic assessment used across studies as well as the higher intensity of HIIE and SIE which requires additional oxygen transport to working muscle. Stroke volume depends on many factors including heart size and compliance as well as venous return, blood volume, mean arterial pressure, and sympathetic input [37]. Nevertheless, we did not measure these outcomes in the present study so we can only speculate why SV was higher in response to interval exercise. However, our rise in SV during SIE and HIIE parallels previous data [9] in paraplegics performing submaximal exercise. In contrast, another study [38] showed no change in SV and dramatic reliance on HR during progressive arm cycling in men with paraplegia $\left(\mathrm{VO}_{2} \mathrm{max}=30 \mathrm{~mL} / \mathrm{kg} / \mathrm{min}\right)$ despite a $45 \%$ increase in oxygen uptake. These conflicting data merit further study concerning cardiovascular responses to exercise in SCI, especially considering that adaptations required to enhance $\mathrm{VO}_{2} \max$ of the arms, the primary muscle mass exercised in this population, likely differ from that of the legs [37].

Peak CO equal to 86 and $83 \% \mathrm{CO}_{\text {peak }}$ during HIIE and SIE was similar to values previously reported during arm ergometry [30, 39] and FES cycling [40] in persons with SCI as well as in able-bodied men performing HIIE or SIE $[20,21]$. Within our sample, men with paraplegia and tetraplegia showed similar resting $\mathrm{CO}(5-6 \mathrm{~L} / \mathrm{min})$, although 
$\mathrm{CO}_{\text {peak }}$ was twofold higher in paraplegics versus tetraplegics. The lower $\mathrm{CO}$ in tetraplegics is explained by a smaller muscle mass as well as attenuated venous return [41]. Whether $\mathrm{CO}$ is enhanced with chronic training is equivocal, as Hooker et al. [42]. showed no change in CO in response to 36 sessions of electrically stimulated cycling; whereas, CO was increased after 24 sessions of hybrid interval training [43]. These discrepant results may be due to higher intensity of interval training, which in active men and women led to increased CO due to increased SV [44].

Our findings of marked increases in oxygen uptake in response to interval training (Fig. 2) support data in men with SCI completing HIIE and SIE at 70 and $105 \%$ PPO, in which peak $\mathrm{VO}_{2}$ during HIIE and SIE was equal to 90 and $80 \% \mathrm{VO}_{2}$ peak [27]. These results denote a substantial metabolic strain from interval exercise that exceeds the oxygen cost of circuit training [45], FES cycling [46], and exoskeleton-assisted walking [47]. $\mathrm{VO}_{2} \max$ is a primary determinant of mortality risk as well as cardiovascular health in able-bodied individuals [48, 49]. In persons with $\mathrm{SCI}, \mathrm{VO}_{2}$ peak increases with completion of prolonged arm ergometry [50]; however, MICE may not improve many cardiometabolic risk factors [33] which warrants study of the efficacy of exercise regimes such as HIIT in this population. Our HIIE and SIE regimes required 60 and $30 \mathrm{~s}$ efforts at 85 and $115 \%$ PPO, respectively, which were welltolerated with no side effects. Compared to MICE, interval exercise elicits similar activation of several signaling pathways involved in mitochondrial biogenesis and energy metabolism including phosphorylation of adenosine monophosphate-activated protein kinase and p53 [51], which may contribute to superior increases in $\mathrm{VO}_{2} \max$ [15] and glycemic control [16] reported in able-bodied individuals. Overall, interval exercise may be a viable alternative to MICE for adults with SCI due to its substantial health and fitness-related benefits, although additional study is needed to verify this claim.

Our study has some limitations. First, we recruited a small sample differing in injury level which leads to varied degrees of autonomic function in our participants, which we did not consider in our study. The small sample may decrease statistical power leading to no significant differences in some responses between HIIE/SIE and MICE. Second, we included men with paraplegia and tetraplegia who have unique hemodynamic responses, yet we had an inadequate number of each to identify effects of injury level. However, our sample size and demographics are similar to those previously used $[11,19,28-30,35,52]$. Third, we recruited active men, so our results do not apply to inactive individuals. Fourth, thoracic impedance has been validated in able-bodied people [24] and individuals with heart disease [53] to estimate hemodynamic responses.
However, previous studies in SCI utilized Innocor ${ }^{\circledR}[54]$ and $\mathrm{CO}_{2}$ rebreathing $[9,30,55]$ to measure hemodynamic responses. Future studies should explore the validity of thoracic impedance in SCI compared to other methods.

\section{Conclusion}

In active men with SCI, hemodynamic and cardiorespiratory responses significantly increased to near-maximal values with completion of HIIE and SIE, similar to that seen in able-bodied individuals. The fact that interval bouts are well-tolerated and elicit near-maximal responses greater than that induced from moderate exercise potentially justify its implementation in populations including those with SCI who have low fitness. Further research is warranted to determine if chronic HIIE can augment hemodynamic responses in SCI which will potentially lead to enhanced cardiovascular and physical function and overall health status.

\section{Data Archiving}

The author will gladly share our data with any individuals who are interested.

Acknowledgements The author appreciates the participants for their allocation of time in completing this study. In addition, he acknowledges Elyse Palumbo and Jackie Godinez for assistance in data collection.

Funding This project was partially funded by Grant Proposal Seed Money at CSU-San Marcos.

\section{Compliance with ethical standards}

Conflict of interest The author declares that he has no conflict of interest.

Publisher's note: Springer Nature remains neutral with regard to jurisdictional claims in published maps and institutional affiliations.

\section{References}

1. Cragg JJ, Noonan VK, Krassioukov A, Borisoff J. Cardiovascular disease and spinal cord injury: results from a national population health survey. Neurology. 2013;81:723-8.

2. Myers J, Lee M, Kiratli J. Cardiovascular disease in spinal cord injury: an overview of prevalence, risk, evaluation, and management. Am J Phys Med Rehabil. 2007;86:142-52.

3. Nash M, Tractenberg RE, Mendez AJ, Ljungber IH, Tinsley EA, Burns-Drecq PA. Cardiometabolic syndrome in people with spinal cord injury/disease: guideline-derived and nonguideline risk components in a pooled sample. Arch Phys Med Rehabil. 2016;97:1696-705. 
4. Phillips AA, Krassioukov AV. Contemporary cardiovascular concerns after spinal cord injury: mechanisms, maladaptions, and management. J Neurotrauma. 2015;32:1927-42.

5. Bauman WA, Spungen AM. Coronary heart disease in individuals with spinal cord injury: assessment of risk factors. Spinal Cord. 2008;46:466-74.

6. Phillips WT, Kiratli BJ, Sarkarati M, Weraarchakul G, Myers J, Franklin BA, et al. Effect of spinal cord injury on the heart and cardiovascular fitness. Curr Probl Cardiol. 1998;23:641-716.

7. Ginis KA, Arbour-Nicitopoulos KP, Latimer AE, Buchholz AC, Bray SR, Craven BC, et al. Leisure time physical activity in a population-based sample of people with spinal cord injury part II: activity types, intensities, and durations. Arch Phys Med Rehabil. 2010;91:729-33.

8. Lavis TD, Scelza WM, Bockenek WL. Cardiovascular health and fitness in persons with spinal cord injury. Phys Med Rehabil Clin N Am. 2007;18:317-31.

9. Hopman MTE, Oeseburg B, Binkhorst RA. Cardiovascular responses in paraplegic subjects during arm exercise. Eur J Appl Physiol. 1992;65:73-78.

10. Bell JW, Chen D, Bahls M, Newcomer SC. Altered resting hemodynamics in lower- extremity arteries of individuals with spinal cord injury. J Spinal Cord Med. 2013;36:104-11.

11. Thijssen DH, Steendjik S, Hopman MT. Blood redistribution during exercise in subjects with spinal cord injury and controls. Med Sci Sports Exerc. 2009;41:1249-54.

12. Rodrigues D, Tran Y, Guest R, Middleton J, Craig A. Influence of neurological lesion level on heart rate variability and fatigue in adults with spinal cord injury. Spinal Cord. 2016;54:292-7.

13. Hicks AL, Martin K, Ditor D, Latimer A, Craven C, Bugaresti J, et al. Long-term exercise training in persons with spinal cord injury: effects on strength, arm ergometry performance, and psychological well-being. Spinal Cord. 2003;41:34-43.

14. Davis GM, Shepard RJ. Cardiorespiratory fitness in highly-active versus inactive paraplegics. Med Sci Sports Exerc. 1988;20:463-8.

15. Jelleyman C, Yates T, O’Donovan G, Gray LJ, King JA, Khunti $\mathrm{K}$, et al. The effects of high-intensity interval training on glucose regulation and insulin resistance: a meta-analysis. Obes Rev. 2015;16:942-61.

16. Weston KS, Wisloff U, Coombes JS. High-intensity interval training in patients with lifestyle-induced cardiometabolic disease: a systematic review and meta-analysis. $\mathrm{Br} \mathrm{J}$ Sports Med. 2014;48:1227-34.

17. Milanovic Z, Sporis G, Weston M. Effectiveness of high-intensity interval training (HIT) and continuous endurance training for $\mathrm{VO}_{2}$ max improvements: a systematic review and meta-analysis of controlled trials. Sports Med. 2015;45:1469-81.

18. Gillen JB, Martin BJ, MacInnis MJ, Skelly LE, Tarnopolsky MA, Gibala MJ. Twelve weeks of sprint interval training improves indices of cardiometabolic health similar to traditional endurance training despite a five-fold lower exercise volume and time commitment. PLoS ONE. 2016;11:1-14.

19. Astorino TA, Thum JS. Interval training elicits higher enjoyment versus moderate exercise in persons with spinal cord injury. J Spinal Cord Med. 2018;41:77-84.

20. Zafeiridis A, Kounoupis A, Dipla K, Kyparos A, Nikolaidis MG, Smilios I, et al. Oxygen delivery and muscle deoxygenation during continuous, long-and short-interval exercise. Int J Sports Med. 2015;36:872-80.

21. Horn T, Roverud G, Sutzko K, Browne M, Parra C, Astorino TA. Single session of sprint interval training elicits similar cardiac output but lower oxygen uptake versus ramp exercise to exhaustion in men and women. Int $\mathrm{J}$ Physiol Pathophysiol Pharmacol. 2016;8:87-94.
22. Washburn RA, Zhu W, McAuley E, Frogley M, Figoni SF. The physical activity scale for individuals with physical disabilities: development and evaluation. Arch Phys Med Rehab. 2002;83:193-200.

23. Pescatello LS, Arena R, Riebe D, Thompson PD (eds). ACSM's Guidelines for Exercise Testing and Prescription. (Wolters Kluwer/Lippincott Williams \& Wilkins, Philadelphia, 2014).

24. Charloux A, Lonsdorfer-wolf E, Richard R, Oswald-Mammosser M, Mettauer B, Geny B, et al. A new impedance cardiograph device for the non-invasive evaluation of cardiac output at rest and during exercise: comparison with the "direct" Fick method. Eur J Appl Physiol. 2000;82:313-20.

25. Payseur JD, Rigney JJ, Turner SL, Wu X, Murphy DJ, Rossman EI. Evaluation of a method utilizing PhysioFlow ${ }^{\circledR}$, a novel signal morphology-based form of impedance cardiography, to measure cardiac output in the conscious beagle. J Pharmacol Toxicol Meth. 2016;81:115-9.

26. Borg G. Borg's perceived exertion and pain scales. Champaign: Human Kinetics; 1998.

27. Astorino TA, Thum JS. Within-session responses to high-intensity interval training in spinal cord injury. Disabil Rehabil. 2018;40:444-9.

28. Bresnahan JJ, Farkas GJ, Clasey JL, Yates JW, Gater DR. Arm crank ergometry improves cardiovascular disease risk factors and community mobility independent of body composition in high motor complete spinal cord injury. J Spinal Cord Med. 2018;15:1-21.

29. Jacobs KA, Burns P, Kressler J, Nash MS. Heavy reliance on carbohydrate across a wide range of exercise intensities during voluntary arm ergometry in persons with paraplegia. J Spinal Cord Med. 2013;36:427-35.

30. Hostettler S, Leuthold L, Brechbühl J, Mueller G, Illi SK, Spengler CM. Maximal cardiac output during arm exercise in the sitting position after cervical spinal cord injury. J Rehabil Med. 2012;44:131-6.

31. Tschakert G, Kroepfl JM, Mueller A, Harpf H, Harpf L, Traninger $\mathrm{H}$, et al. Acute physiological responses to short- and long-stage high-intensity interval exercise in cardiac rehabilitation: a pilot study. J Sports Sci Med. 2016;15:80-91.

32. Nightingale TE, Metcalfe RS, Vollaard NBJ, Bilzon J. Exercise guidelines to promote cardiometabolic health in spinal cord injured humans: time to raise the intensity? Arch Phys Med Rehabil. 2017;98:1693-704.

33. Totosy de Zepetnek JO, Pelletier CA, Hicks AL, MacDonald MJ. Following the physical activity guidelines for adults with spinal cord injury for 16 weeks does not improve vascular health: a randomized controlled trial. Arch Phys Med Rehabil. 2015;96:1566-75.

34. Janicki JS, Sheriff DD, Robotham JL, Wise RA. Cardiac output during exercise: contributions of the cardiac, circulatory, and respiratory systems. In: Rowell LB, Shepherd JT, (eds). Handbook of Physiology, Section 12. Exercise: regulation and integration of multiple systems. American Physiological Society, Bethesda, 1996) pp. 649-704.

35. Hjeltnes N. Oxygen uptake and cardiac output in graded arm exercise in paraplegics with low level spinal lesions. Scand J Rehab Med. 1977;9:107-13.

36. Kinzer SM, Convertino VA. Role of leg vasculature in the cardiovascular response to arm work in wheelchair-dependent populations. Clin Physiol. 1989;9:525-33.

37. Calbet JAL, Gonzalez-Alonso J, Helge JW, Sondergaard H, Munch-Anderson T, Saltin B, et al. Central and peripheral hemodynamics in exercising humans: leg vs arm exercise. Scand J Med Sci Sports. 2015;25(S4):144-57. 
38. Hopman MT, Pistorius M, Kamerbeek IC, Binkhorst RA. Cardiac output in paraplegic subjects at high exercise intensities. Eur $\mathbf{J}$ Appl Physiol Occup Physiol. 1993;66:531-7.

39. Jehl JL, Gandmontagne M, Pastene G, Eyssette M, Flandrois R, Coudert J. Cardiac output during exercise in paraplegic subjects. Eur J Appl Physiol. 1991;62:256-60.

40. Davis GM, Servedio FJ, Glaser RM, Gupta SC, Suryaprasad AG. Cardiovascular responses to arm-cranking and FNS-induced leg exercise in paraplegia. J Appl Physiol. 1990;69:1-7.

41. Van Loan M, McCluer S, Loftin JM, Boileau RA. Comparison of physiological responses to maximal arm exercise among able-bodied, paraplegics, and quadriplegics. Paraplegia. 1987;25:397-405.

42. Hooker SP, Figoni SF, Rodgers MM, Glaser RM, Mathews T, Suryaprasad AG, et al. Physiologic effects of electrical stimulation leg cycle exercise training in spinal cord injured persons. Arch Phys Med Rehabil. 1992;73:470-6.

43. Brurok B, Helgerud J, Karlsen T, Leivseth G, Hoff J. Effect of aerobic high-intensity hybrid training on stroke volume and peak oxygen consumption in men with spinal cord injury. Am J Phys Med Rehabil. 2011;90:407-14.

44. Astorino TA, Edmunds RM, Clark A, King L, Gallant RA, Namm $\mathrm{S}$, et al. High-intensity interval training increases cardiac output and $\mathrm{VO}_{2} \max$. Med Sci Sports Exerc. 2017;49:265-73.

45. Nash MS, Jacobs PL, Woods JM, Clark JE, Pray TA, Pumarejo AE. A comparison of 2 circuit exercise training techniques for eliciting matched metabolic responses in persons with paraplegia. Arch Phys Med Rehabil. 2002;83:201-9.

46. Hettinga DM, Andrews BJ. Oxygen consumption during functional electrical stimulation-assisted exercise in persons with spinal cord injury: implications for fitness and health. Sports Med. 2008;38:825-38.

47. Evans N, Hartigan C, Kandilakis C, Pharo E, Clesson N. Acute cardiorespiratory and metabolic responses during exoskeleton- assisted walking overground among persons with chronic spinal cord injury. Top Spinal Cord Inj Rehabil. 2015;21:122-32.

48. Myers J, Prakash M, Froelicher V, Do D, Partington S, Atwood JE. Exercise capacity and mortality among men referred for exercise testing. N Engl J Med. 2002;346:793-801.

49. Lee DC, Sui XM, Artero EG, Lee IM, Church TS, McAuley PA, et al. Long-term effects of changes in cardiorespiratory fitness and body mass index on all-cause and cardiovascular disease mortality in men: the aerobics center longitudinal study. Circulation. 2011;124:2483-90.

50. De Groot PC, Hjeltnes N, Heijboer AC, Stal W, Birkeland K. Effect of training intensity on physical capacity, lipid profile and insulin sensitivity in early rehabilitation of spinal cord injured individuals. Spinal Cord. 2003;41:673-9.

51. Gibala MJ, Gillen JB, Percival ME. Physiological and healthrelated adaptations to low- volume interval training: influences of nutrition and sex. Sports Med. 2014;44(S2):S127-37.

52. Bell JW, Chen D, Bahls M, Newcomer SC. Evidence for greater burden of peripheral arterial disease in lower extremity arteries of spinal cord-injured individuals. Am J Physiol Heart Circ Physiol. 2011;301:H766-72.

53. Legendre A, Bonnet D, Bosquet L. Reliability of peak exercise stroke volume assessment by impedance cardiography in patients with residual right outflow tract lesions after congenital heart disease repair. Pediatr Cardiol. 2018;39:45-50.

54. Hostettler S, Leuthold L, Brechbühl J, Mueller G, Illi SK, Spengler CM. Reliability of non-invasive cardiac output measurement in individuals with tetraplegia. Spinal Cord. 2011;49:665-71.

55. Myers J, Brown H, Smith S, Perkash I, Kiratli BJ. Reproducibility of noninvasive cardiac output during arm exercise in spinal cord injury. J Rehabil Res Dev. 2007;44:747-52. 